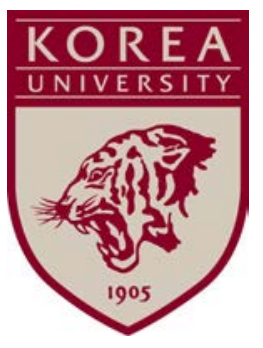

Discussion Paper Series

No. 1901

August, 2019

\title{
Home Advantage in Skeleton: Familiarity versus Crowd Support
}

Seungwhan Chun

Sang Soo Park

The Institute of Economic Research - Korea University

Anam-dong, Sungbuk-ku, Seoul, 136-701, South Korea, Tel: (82-2) 3290-1632, Fax: (82-2) 928-4948

Copyright (C) 2019 IER. 


\title{
Home Advantage in Skeleton:
}

\section{Familiarity versus Crowd Support}

\author{
Seungwhan Chun*and Sang Soo Park ${ }^{\dagger}$
}

August 2, 2019

\begin{abstract}
This paper investigates the existence of home advantage in the individual winter sport skeleton and identifies two sources of advantage: support from the crowd and familiarity with the track. In the Olympics and the World Championships, home advantage leads to about a $0.854 \%$ improvement in performance on average, of which $0.444 \%$ points are due to crowd support and 0.410-points are due to familiarity. In the the development circuits (the Intercontinental Cup, North American Cup, and European Cup), the crowd effect is not as significant and the effect of familiarity is more dominant. Another interesting finding is that speeds in the Olympics are faster than in the World Championships on average, which may represent the motivational effect of the Olympics, although we were not able to control for the quality of the tracks.
\end{abstract}

Keywords: Home advantage, familiarity, crowd support, skeleton, sledding sports, fixed effects

${ }^{*}$ Department of Economics, Korea University, Seoul, South Korea. winforchamp@korea.ac.kr

${ }^{\dagger}$ Department of Economics, Korea University, Seoul, South Korea. starpac@korea.ac.kr 


\section{Introduction}

The traditional definition of home advantage is "the consistent finding that home teams in sport competitions win over $50 \%$ of the games played under a balanced home and away schedule' (Courneya \& Carron, 1992). Thus, significant attention has been paid to home advantage in team sports, where seasons typically consist of an equal number of home and away games. On the other hand, home advantage in individual sports is less certain due to the typically unbalanced home and away schedule and the fact that many individual sports involve races, where results are determined by ranking not by one-on-one match ups.

Soccer is one of the most studied sports in terms of home advantage. Dowie (1982), Pollard (1986), and Clarke and Norman (1995) reported the existence of home advantage in English football leagues, while Pollard and Gómez (2014) conducted extensive research to reveal significant home advantage in most of the 157 national soccer leagues. Home advantage in professional leagues has also been reported for baseball (Schwartz \& Barsky, 1977; Pollard \& Pollard, 2005), basketball (Schwartz \& Barsky, 1977; Pollard \& Pollard, 2005; Boudreaux, Sanders \& Walia, 2017), ice hockey (Schwartz \& Barsky, 1977; Pollard \& Pollard, 2005; Leard \& Doyle, 2011), American football (Pollard \& Pollard, 2005), rugby (Morton, 2006), Australian football (Clarke, 2005), and Gaelic football (Rooney \& Kennedy, 2018) though the size of this advantage varies by sport.

To the best of our knowledge, McCutcheon (1984) was the first paper to investigate home advantage in individual sports, reporting no significant advantage for home teams in high school cross-country. Alpine skiing (Bary \& Carron, 1993), speed skating (Koning, 2005), skeleton (Bullock, Hopkins, Martin \& Marino, 2009) and events in the Olympics (Balmer, Nevill, \& Williams, 2001, 2003) are also individual sports for which home advantage has been investigated. For the individual sports with one-on-one match ups, Koning (2011) identified home advantage for male professional tennis athletes, while Balmer, Nevill and Lane (2005) reported a higher frequency of home wins in European championship boxing. In addition, Krumer (2017) and Ferreira Julio, Panissa, Miarka, Takito, and Franchini (2013) documented 
home advantage in judo.

Our study aims to investigate home advantage for the individual winter sport of skeleton. Skeleton is a sledding sport in which an athlete rides a sled down an ice track headfirst while lying down. Balmer et al. (2001) investigated home advantage in Winter Olympics events between 1908 and 1998 based on the medals won by country. They found limited home advantage for the sledding sports bobsleigh and luge over other events; skeleton was not included in their research because it was held only twice during their study period. Our research differs from Balmer et al. (2001) in that we use a wide variety of skeleton competitions and not just the Olympics. Similarly, Koning (2005) identified a significant home advantage $0.2 \%$ for speed skating times and found evidence for crowd and familiarity effects among four known home advantage effects (crowd, travel, familiarity, and rule effects). We exploited two stages of skeleton heats, the pushing and sliding stages to separate out the effects of the crowd support from familiarity with the track. Lastly, Bullock et al. (2009) reported significant home advantage for women skeleton athletes in World Cup races between 2002 and 2006. We also analyze the results of the World Cup races but with more than four competition seasons. In addition, other skeleton series are used to determine whether the strength of home advantage varies with the type of competition. Our approach also differs from Bullock et al. (2009) in terms of the identification strategy and the isolation of two different factors.

The structure of this article is as follows. Section 2 discusses home advantage in skeleton. In the third section, data and descriptive statistics are presented. Section 4 then introduces the model used in this article. We presents the results in Section 5. The last section concludes the paper. 


\section{Home Advantage in Skeleton}

In skeleton, a single ride is a heat, or known as a run. At the beginning of each heat, the athlete propels the sled by running in a crouching position holding onto the sled for the first 50 meters, i.e. the pushing stage. The speed obtained at the end of this stage is crucial for success in skeleton competitions (Zanoletti, La Torre, Merati, Rampinini \& Impellizzeri, 2006). After this stage, the athlete jumps onto the sled head first and steers the sled down the hill until the finish line, i.e. the sliding stage. Steering during the sliding stage is another important skill in a skeleton race. Too much steering control can lead to skidding, increasing the run time, while too little can lead to uncontrollable speed and a crash. Because sledding tracks vary in length, the number of curves, and gradient, it is important for athletes to plan an appropriate steering strategy for each course.

During a run, times are recorded at several points on the track. The time an athlete takes to reach the first 50 meters is called the start time and the time it takes to reach the finish line is called the run time or the final time. After the athletes have all finished their heats (two, three, or four heats depending on the competition), the combined run times for all heats determine the rankings. In this sense, home advantage in skeleton can be defined in terms of the run times. Because tracks differ in various aspects, including their lengths, we normalize the run times by converting them to average track speeds, which is the run time divided by the length of track, in order to take into account differences in track length. Thus, home advantage in skeleton in our paper means the consistent finding that a home athlete in a skeleton competition improves average speed of a race compared to that in away competitions with similar conditions.

The mechanisms behind home advantage have drawn the interest of sports scholars. In a seminal paper in the field, Courneya and Carron (1992) suggested four potential factors related to home advantage: crowd, travel, familiarity, and rules. Support from the home crowd can motivate the home team, demoralize the away team, and influence referee decisions. Dowie (1982) and Pollard (1986) reported that home advantage in English football leagues 
did not depend on crowd sizes, whereas Schwartz and Barsky (1977) found that home advantage in Major League Baseball increased with crowd size. Recently, Boudreax et al. (2017) and Ponzo and Scoppa (2018) isolated crowd support from the other factors by analyzing same-stadium derbies. In the study by Boudreax et al. (2017), two National Basketball Association teams sharing the same stadium in LA offered a natural experiment to quantify the crowd effect. It was found that support from the home crowd increased the likelihood of a win by nearly 22 percentage points. Ponzo and Scoppa (2018) analyzed the Italian soccer league Serie A in which several teams use the same stadiums, and reported a notable crowd effect. Several studies have indicated that one of the possible reasons for the crowd effect is referee bias arising from referees experiencing crowd noise as a form of social pressure (Balmer, Nevill \& Lane, 2005; Boyko, Boyko \& Boyko, 2007; Dawson \& Dobson, 2010; Dawson, Dobson, Goddard \& Wilson, 2007; Dohmen, 2008; Picazo-Tadeo, González-Gómez \& Guardiola, 2017; Sutter \& Kocher, 2004).

The travel factor, or the fatigue effect, appears when an away team performs poorly due to increased fatigue after a long journey to an away game. Goumas (2014) reported that home teams in the Australian soccer league A-League won more competition points when the away team had to cross several time zones and thus suffered jet lag. Nichols (2014) also reported that the probability of home team wins in the National Football League increased when a visiting team crossed at least one time zone, while Oberhofer, Philippovich and Winner (2010) identified non-monotonic effects of distance on team performance in the German professional soccer league. In contrast, Nutting (2010) and Scoppa (2015) found no travel or fatigue effect in the NBA and international soccer tournaments, respectively.

The effects of familiarity and rules have received less attention in terms of home advantage. Familiarity with the playing venue increases home advantage in the sense that home teams can take advantage of their familiar local environment. However, most research has found no familiarity effects in several sports. Dowie (1982) found that the home advantage of English soccer teams did not vary with the size of the playing area, while Moore and 
Brylinsky (1995) showed that home advantage for Western Michigan University basketball teams did not decrease when using temporary home courts while a new home court was under construction. Interestingly, Pollard (2002) and Loughead, Carron, Bray, and Kim (2003) reached the opposite conclusion on the effect of familiarity in several team sports, even though they used similar samples. Finally, rule advantages may be available for home teams. For example, Courneya and Carron (1990) found no home advantage from batting last in softball, whereas Leard and Doyle (2011) suggested that home advantage in the National Hockey League could be explained to some degree by its face-off rule.

Of the four possible factors affecting home advantage, skeleton is most likely to be affected by the crowds and familiarity. However, the effect of crowds may be more limited for skeleton races than for other sports for a number of reasons. First, the spectator capacity of a track is very limited. For example, the Alpensia Sliding Centre in Pyeongchang, South Korea, which held the 2018 Winter Olympics, can accommodate only 7000 spectators. Second, seats are not evenly distributed next to the track. Most of the seats are located at the start or finish, with the rest spread sparsely alongside the track. Third, it is difficult for the crowd noise to reach the athletes during a ride, during which they can reach speeds of up to $130 \mathrm{~km} / \mathrm{h}$. Finally, referee bias caused by the noise of the home crowd is not likely to be a factor in skeleton because the rankings are not determined by referees. Therefore, it is safe to assume that the crowd noise can only affect athletes in the starting area, where they sprint to gather sled speed. If a crowd effect exists, then the speed of home athletes at the pushing stage should be higher.

Familiarity, on the other hand, is likely to be the main driver behind home advantage in skeleton, assuming it exists. As noted above, good steering skills are a must for athletes. If an athlete can adapt to a track through a considerable number of practice rides, it is highly likely that they can develop and practice an optimal steering strategy and appropriate skills for the track. Thus, athletes can benefit from their familiarity with their home track because they have frequent access to the tracks for practice rides. Familiarity, again if it exists, will be 
most important in the sliding stage because the first 50 meters are too short for familiarity to affect the speed of the athlete to a meaningful degree and, more importantly, the starting area of most tracks are the same. The familiarity effect is also expected to be greater in top competitions, such as the Olympics, where host countries, in their pursuit of medals, will give their athletes unlimited access to the facilities.

On the other hand, the effects of travel fatigue and home-ground rules are expected to be negligible in skeleton. Each competition includes at least three official training days prior to race day. These training days, in addition to additional rest periods, would give athletes sufficient time for recovery. In addition, the limited number of official tracks for competitions would allow athletes to handle time differences or jet lag. Finally, there is no rule advantage for home athletes. Obviously, the result of skeleton is determined by race times, leaving no room for officials to intervene. In addition, race order is determined by IBSF rankings or the results of the prior heat, which means nationality is not an issue.

In summary, we conclude that, of the four potential factors that affect home advantage, only crowd support (the increase in speed due to crowd support) and familiarity with the course (the increase in speed due to track familiarity) will play crucial roles in skeleton. This paper explicitly isolates the effect of these factors by using the race times at different points using a unique identification strategy made possible by the nature of skeleton.

\section{$3 \quad$ Data and Descriptive Statistics}

Based on our understanding of home advantage in skeleton, we seek to identify the effect of crowd support by analyzing the pushing stage and the effect of track familiarity by analyzing the sliding stage. The outcome variable for the pushing stage is the average speed for the first 50 meters, which is the start time, i.e. the pushing stage time, divided by the interval length (50 meters) converted to $\mathrm{km} / \mathrm{h}$. We refer to this as the pushing stage speed $(y 1)$. The outcome variable for the sliding stage is the average speed for the remainder of the track, 
referred to as the sliding stage speed $(y 2)$. The following formula can be used to compute the sliding stage speed:

$$
\text { sliding stage } \operatorname{speed}(y 2)=\frac{\text { final time }- \text { start time }}{\text { track competition length }-50 m} \text {. }
$$

The sliding stage speed is also converted to $\mathrm{km} / \mathrm{h}$.

We used the official results from 13 seasons between the 06/07 and the 18/19 seasons. The data were obtained from the official website of the International Bobsleigh \& Skeleton Federation (IBSF). Six major skeleton series - tiers of competitions - were chosen for our analysis: the Olympics, the World Championships, the World Cup, the Intercontinental Cup, the North American Cup, and the Europe Cup. The race times from the 2006 Turin Winter Olympics, taken from an official document from the LA84 Foundation Digital Library website, were added for the analysis of the Olympic games. We removed competitions that were canceled due to weather conditions or for which the pushing stage time was not available on the website. In addition, the times of athletes who were disqualified (DSQ), did not start (DNS), or did not finish (DNF) were removed from the analysis. As a result, the total number of the observations used in the analysis was 33,951 rides by 946 athletes over 794 competitions. We also had access to information on 17 competition tracks from the IBSF website. Table 1 shows the details of these tracks. The tracks differ in competition length, average gradient, vertical drop, the number of curves, and start altitude, thus requiring different steering strategies to be employed according to each track's characteristics. The 17 tracks were located in 12 countries, while athletes in our data set came from 53 countries.

Table 2 provides a summary of the observations used in the analysis. Nearly $14 \%$ of the total observations were from home athletes (athletes from the host countries). Note that sliding stage speed was about 2.7 times faster than the pushing stage speed in terms of the mean and the maximum speed. This shows that gravity plays a critical role in a sledder's speed. The lower tail of the speed distributions was partly due to athletes who fell 
Table 1: Characteristics of the sledding tracks analyzed in the present study

\begin{tabular}{lcccccc}
\hline & $\begin{array}{c}\text { Competition Average } \\
\text { length }\end{array}$ & $\begin{array}{c}\text { Vertical } \\
\text { gradient }\end{array}$ & Curves & $\begin{array}{c}\text { Start } \\
\text { dltitude }\end{array}$ & Opened \\
\hline Altenberg (GER) & 1413 & 8.66 & 122.22 & 17 & 785 & 1986 \\
Calgary (CAN) & 1494 & 8 & 121 & 19 & 1251 & $1986^{\mathrm{a}}$ \\
Cesana (ITA) & 1435 & 9.2 & 117 & 19 & 1674 & $2005^{\mathrm{b}}$ \\
Innsbruck (AUT) & 1218 & 9 & 124 & 14 & 1124 & 1975 \\
Königssee (GER) & 1251.2 & 9 & 120 & 16 & 1675.4 & 1990 \\
La Plagne (FRA) & 1507.5 & 8 & 124 & 19 & 1684 & 1992 \\
Lake Placid (USA) & 1455 & 9 & 128 & 20 & 757 & 1997 \\
Lillehammer (NOR) & 1365 & 8 & 114 & 16 & 384 & 1992 \\
Nagano (JPN) & 1360 & 7 & 112 & 15 & 1028 & 1996 \\
Park City (USA) & 1335 & 8 & 104 & 15 & 2232 & 1997 \\
Pyeongchang (KOR) & 1376 & 9.48 & 117 & 16 & 930 & 2016 \\
Salt Lake City (USA) & 1335 & 8 & 104 & 15 & 2232 & 1997 \\
Sigulda (LAT) & 1200 & 8 & 99 & 16 & 117 & 1986 \\
Sochi (RUS) & 1500 & 20 & 124 & 17 & 836 & 2012 \\
St. Moritz (SUI) & 1722 & 8 & 130 & 19 & 1852 & 1904 \\
Whistler (CAN) & 1450.4 & 9 & 148 & 16 & 935 & 2008 \\
Winterberg (GER) & 1330 & 9 & 110 & 15 & 760 & 1977 \\
\hline
\end{tabular}

Notes. ${ }^{\mathrm{a}}$ Indefinitely closed in $2019 .{ }^{\mathrm{b}}$ Closed in the $11 / 12$ season

in the pushing stage or who crashed during the sliding stage. The Track_possess variable was included in order to isolate track familiarity from the effect of skeleton infrastructure. Some sledders from three countries (Italy, South Korea, and Russia) experienced changes in the infrastructure between the 06/07 season and the 18/19 season. The Cesana track in Italy closed during the 11/12 season, while the Pyeongchang (South Korea) and Sochi (Russia) tracks were built before the respective Olympic events. The Age of each athlete was converted to the difference between the birth date and the competition date in days in the actual analysis.

The data also reveals some interesting features regarding skeleton speeds. Table 3 and Table 4 present the descriptive statistics for pushing and sliding stage speeds by series. Firstly, 
Table 2: Descriptive statistics.

\begin{tabular}{|c|c|c|c|c|c|c|}
\hline & Definition & $N$ & Mean & $\mathrm{SD}$ & Min. & Max. \\
\hline Start time & $\begin{array}{l}\text { Time for the first } 50 \\
\text { meters (seconds) }\end{array}$ & 33,951 & 5.30 & 0.45 & 4.47 & 29.57 \\
\hline Final time & Final time (seconds) & 33,951 & 57.51 & 5.28 & 47.44 & 211.54 \\
\hline $\begin{array}{l}\text { Pushing } \\
\text { stage speed }\end{array}$ & $\begin{array}{l}\text { Average speed for the } \\
\text { first } 50 \text { meters }(\mathrm{km} / \mathrm{h})\end{array}$ & 33,951 & 34.19 & 2.49 & 6.09 & 40.27 \\
\hline $\begin{array}{l}\text { Sliding stage } \\
\text { speed }\end{array}$ & $\begin{array}{l}\text { Average speed for the } \\
\text { rest of the track } \\
(\mathrm{km} / \mathrm{h})\end{array}$ & 33,951 & 92.61 & 6.52 & 20.98 & 106.43 \\
\hline Host & $\begin{array}{l}\text { Dummy variable equal } \\
\text { to } 1 \text { if the athlete is a } \\
\text { home athlete }\end{array}$ & 33,951 & 0.14 & 0.34 & 0 & 1 \\
\hline Track_possess & $\begin{array}{l}\text { Dummy variable equal } \\
\text { to } 1 \text { if the nation of } \\
\text { the athlete has a } \\
\text { sledding track }\end{array}$ & 33,951 & 0.66 & 0.47 & 0 & 1 \\
\hline Male & $\begin{array}{l}\text { Dummy variable equal } \\
\text { to } 1 \text { if an athlete is } \\
\text { male }\end{array}$ & 33,951 & 0.56 & 0.50 & 0 & 1 \\
\hline $\operatorname{Age}^{a}$ & $\begin{array}{l}\text { Age on the } \\
\text { competition date }\end{array}$ & 33,951 & 26.28 & 5.59 & 13.96 & 53.62 \\
\hline
\end{tabular}

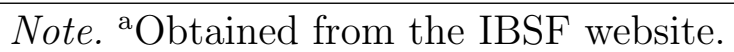

the mean speeds at the Olympics were the fastest of the series. There are two possible reasons for this: being in the Olympics is a motivation for an athlete to exert more effort. Most of the participants in the Olympics are top ranking athletes according to the IBSF rankings, which may explain the small standard deviation for the speeds at the Olympics. Secondly, the mean sliding speed at the Europe Cup was noticeably lower than the mean speeds of other series, while that of the North American Cup was close to that of the Olympics. This might be due to the fact that the two continental cups are held in their respective continents, so the differences in track characteristics of two continents might contribute to the difference in the mean sliding speed. 
Table 3: Pushing stage speed by series

\begin{tabular}{cccccc} 
Series & $N$ & Mean & SD & Min. & Max. \\
\hline Olympics & 631 & 36.59 & 1.53 & 33.03 & 40.27 \\
World Championships & 2135 & 34.70 & 2.26 & 26.12 & 40.27 \\
World Cup & 9205 & 34.68 & 2.32 & 19.72 & 40.27 \\
Intercontinental Cup & 6944 & 34.39 & 2.32 & 9.28 & 40.00 \\
Europe Cup & 8712 & 33.24 & 2.63 & 6.09 & 39.13 \\
North American Cup & 6324 & 34.13 & 2.40 & 19.23 & 40.00 \\
\hline
\end{tabular}

Table 4: Sliding stage speed by series

\begin{tabular}{cccccc} 
Series & $N$ & Mean & SD & Min. & Max. \\
\hline Olympics & 631 & 99.53 & 4.41 & 86.10 & 106.02 \\
World Championships & 2135 & 92.70 & 5.62 & 77.36 & 106.43 \\
World Cup & 9205 & 93.65 & 6.18 & 77.01 & 106.20 \\
Intercontinental Cup & 6944 & 93.67 & 6.45 & 20.98 & 104.86 \\
Europe Cup & 8712 & 86.87 & 4.79 & 39.35 & 99.71 \\
North American Cup & 6324 & 97.11 & 3.11 & 42.91 & 104.92 \\
\hline
\end{tabular}

\section{Identification Strategy and Models}

It is reasonable to assume that the size of the home advantage will be proportional to the athletes' speeds, so we use $\ln y 1$ and $\ln y 2$ instead of $y 1$ and $y 2$ as our dependent variables. Let $y_{i h c s t}$ be either the pushing stage speed $(y 1)$ or the sliding stage speed $(y 2)$ of athlete $i$ in heat $h \in\{1,2, \cdots\}$ of $c$ competition of series $s$ held at $t$ season. In a general form, we can set the following model:

$$
\ln y_{i h c s t}=\beta_{0, h}+\beta_{H} \text { Host }_{i c s t}+\beta_{\text {o.v. }} \mathrm{O} . \mathrm{V}_{\cdot i h c s t}+\eta_{i}^{\text {ind }}+\eta_{s}^{\text {series }}+\varepsilon_{\text {ihcst }} .
$$

Host $_{\text {icst }}$ is 1 if $i$ 's country is hosting $c$ of $s$ held in $t$ and 0 otherwise. Coefficient $\beta_{H}$ is the size of the crowd effect (when $y$ is $y 1$ ) or that of the familiarity effect (when $y$ is $y 2$ ). O.V. represents control variables that may affect $\ln y$, which include $i$ 's characteristics, the track and country characteristics of the site where $c$ is held, and the characteristics of the season $t$ when $c$ is held, among others. The specific variables that we use for the other variables will be 
described later in the section. $\epsilon_{i h c s t}$ is an error component with zero mean. It is idiosyncratic across athletes, but we allow for a correlation between the times of a given $i$ for a given $c$ and $t . \beta_{0, h}$ allows for the possibility that $i$ 's times change by heat on average.

There are other unobservable factors that will affect ln $y$. For example, athlete $i$ may have a stronger innate ability to balance on the sled compared to others. $\eta^{\text {ind }}$ is the total effect of such unobservable individual-specific characteristics. In addition, some unobservable factors are series-specific. As mentioned earlier, times in the Olympics are faster in general than in other competitions. Therefore, there are likely to be series-specific unobservable factors that may affect athletes' performances. $\eta^{\text {series }}$ captures the total effect of these series-specific unobservable factors. If we regress $\ln y_{i h c s t}$ on $H_{\text {ost }}$ icst and O.V.ihcst without considering the unobservables $\eta^{\text {ind }}$ and $\eta^{\text {series }}$, then the estimator for $\beta_{H}$ will be inconsistent because $\eta_{i}^{\text {ind }}$ and $\eta_{s}^{\text {series }}$ are very likely to be correlated with Host and, perhaps, some of O.V.

Our identification strategy involves the use of differenced models. It should be noted that the track times of each athlete observed in several competitions represent unbalanced panel data. They are unbalanced in the sense that an athlete does not participate in all competitions in a series. However, for any $i$ who competed at two consecutive competitions $c^{\prime}=c-1$ and $c$ of the same series, potentially in different seasons $t^{\prime}$ and $t$, we can see $y_{i h c^{\prime} s t^{\prime}}$ must satisfy

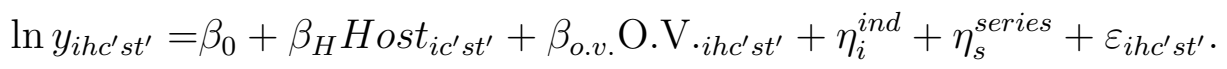

By taking the difference between (2) and (3) with respect to $c$ and $c^{\prime}$, we can eliminate the effects of $\eta^{\text {ind }}$ and $\eta^{\text {series }}$.

$$
\begin{aligned}
\ln y_{i h c s t}-\ln y_{i h c^{\prime} s t^{\prime}}= & \beta_{H}\left(\text { Host }_{i c s t}-H_{o s t} t_{i c^{\prime} s t^{\prime}}\right)+\beta_{\text {o.v. }}(\mathrm{O} \cdot \mathrm{V} \cdot i h c s t \\
& -\mathrm{O} \cdot \mathrm{V} \cdot i h c^{\prime} \mathrm{t}^{\prime} \\
& +\left(\varepsilon_{i h c s t}-\varepsilon_{i h c^{\prime} s t^{\prime}}\right)
\end{aligned}
$$

To simplify the notations, let us define $\Delta_{c,\left(t^{\prime}, t\right)}$, a competition-difference operator between 
the two consecutive competitions $c$ and $c^{\prime}=c-1$ that $i$ participated in, as $\Delta_{c,\left(t^{\prime}, t\right)} W=$ $W_{c, t}-W_{c-1, t^{\prime}}$ for any $W$. Then,

$$
\Delta_{c,\left(t^{\prime}, t\right)} \ln y_{i h s}=\beta_{H} \Delta_{c,\left(t^{\prime}, t\right)} H_{o s t} t_{i s}+\beta_{o . v .} \Delta_{c,\left(t^{\prime}, t\right)} \mathrm{O} . \mathrm{V}_{\cdot i h s}+\epsilon_{i h(c-1, c) s\left(t^{\prime}, t\right)} .
$$

In other words, we can eliminate the effects of $\eta^{\text {ind }}$ and $\eta^{\text {series }}$ and obtain a consistent estimator for $\beta_{H}$ (either the crowd effect or the familiarity effect) by using differenced data for the same athletes between two consecutive competitions. $\epsilon_{i h(c-1, c) s\left(t^{\prime}, t\right)}$ may be correlated with other competition-season's $\epsilon$ 's so we use cluster robust standard errors. Because our dependent variable is $\ln y$, the size of the home advantage is a $100 \times \beta_{H} \%$-point increase (or decrease) in speed.

\subsection{Model for the Familiarity Effect}

Let us begin with the estimation of the familiarity effect. The model for $\ln y 2$ that we use is

$$
\begin{aligned}
\ln y 2_{i h c s t} & =\beta_{0, h}+\beta_{H} \text { Host }_{i c s t}+\beta_{1} \ln y 1_{i h c s t}+X_{i c s t} \beta_{X}+\beta_{p} \text { track_possess } s_{i c s t} \\
& +Z_{c s t} \beta_{Z}+\sum_{\tau \neq 2} \beta_{\tau}^{\text {season }} \text { Season } \tau_{i c t}+\varepsilon_{i h c s t .}
\end{aligned}
$$

It can be assumed that the faster the pushing stage speed is, the faster the sliding stage speed is. Therefore, we need to control for the pushing stage speed in order to isolate the net effect of track familiarity in the sliding stage, hence ln $y 1$ is included as a control variable in the model. $X_{i c s t}$ indicates $i$ 's characteristics at $c$ of $s$ in $t$. Because we will take $\Delta_{c,\left(t^{\prime}, t\right)}$ eventually, time-invariant characteristics will be of no use. Variables such as weight and height would be more suitable control variables but we only have Age (measured in days up to the date of competition $c$ in season $t$ ). The actual $X_{i c s t}$ is $\ln A_{\text {ge }} e_{i c s t}$. The variable track_possess icst $_{\text {is a }}$ dummy variable that takes a value 1 if $i$ 's country has a sledding track at the time of $c$. This is to take into account the effect of training infrastructure in a country, which may magnify 
the effects of home advantage if we do not control for it.

The characteristics of a track included in $Z_{c s t}$ are the competition length $\left(\right.$ Length $\left._{c s t}\right)$, the average gradient in \% (Average gradient $\left.{ }_{c s t}\right)$ between the starting point and finishing point, the height from the finishing point to the starting point in meters (Vertical drop ${ }_{c s t}$ ), the number of curves in the track, and the altitude of the starting point $\left(\right.$ Altitude $\left._{c s t}\right)$. All but the number of curves are log transformed.

Season $1_{\text {ict }}$, Season $2_{i c t}, \cdots$ are season dummies. There are 13 seasons in our dataset, from the $2006 / 07$ to the $2018 / 19$ season. Season 1 is the 2006/07 season, Season 2 is the $2007 / 08$ season, and so on. The season dummies are defined as Seasont $\tau_{i c t}=1$ if $t$ is season $\tau$ and 0 otherwise for $\tau=1, \cdots, 13$. We take Season2, i.e. the 2007/08 season, as our baseline season simply because the Intercontinental Cup was held for the first time then. The inclusion of season dummies is motivated by Koning (2005), who identified improvement in speed skating speeds over time (i.e. from season to season). The coefficients of the season dummies, $\beta_{\tau}^{\text {season }}$, $\tau \in\{1,3, \cdots, 13\}$, can capture the general trend in average speeds over the seasons.

There are six series of different prestige and importance: the Olympics, the World Championships (WCH), the World Cup (WC), the Intercontinental Cup (ICC), the North American Cup (NAC), and the Europe Cup (EC). Since the 2002 Salt Lake City Olympics, where skeleton was reintroduced, the Olympic events are considered the most prestigious. The Olympics are held once every four seasons. The WCH, which is held once at the end of every season except in an Olympics season, is regarded as the top series in skeleton together with the Olympics. Because the Olympics are held once every four years, we have very limited data for Olympic athletes, so we combine the Olympics and the $\mathrm{WCH}$ as one series. The two series combined cover every season and both feature a format that involves four runs. The other series are held at least four times a season. The WC competitions are as important as the $\mathrm{WCH}$ in the sense that the same ranking points are available to the participants in both series. The other three cups, the ICC, NAC, and EC, are often referred to as the development circuits in that they give newcomers an opportunity to gain experience and qualify for the 
$\mathrm{WC}$ and $\mathrm{WCH}$. The ICC falls between the $\mathrm{WC}$ and the two continental cups. The ranking points available in the ICC are lower than in the WC, but higher than in the two continental cups.

The differenced model we use in the estimation for $s=\mathrm{WC}$, ICC, NAC, and EC is

$$
\begin{aligned}
\left(\mathrm{MD}_{2}\right) \Delta_{c,\left(t^{\prime}, t\right)} \ln y 2_{i h s}= & \beta_{H} \Delta_{c,\left(t^{\prime}, t\right)} \text { Host }_{i s}+\beta_{1} \Delta_{c,\left(t^{\prime}, t\right)} \ln y 1_{i h s}+\Delta_{c,\left(t^{\prime}, t\right)} X_{i s} \beta_{X} \\
& +\beta_{p} \Delta_{c,\left(t^{\prime}, t\right)} \text { track_possess }_{i s}+\Delta_{c,\left(t^{\prime}, t\right)} Z_{s} \beta_{Z} \\
& +\sum_{\tau \neq 2} \beta_{\tau}^{\text {season }} \Delta_{c,\left(t^{\prime}, t\right)} \text { Season }_{i} \\
& +\beta_{2}^{\text {Heat }} \text { Heat }_{\text {ih }\left(c^{\prime}, c\right) s\left(t^{\prime}, t\right)}+\epsilon_{i h\left(c^{\prime}, c\right) s\left(t^{\prime}, t\right) .} .
\end{aligned}
$$

There are multiple competitions in each season for these series so $t^{\prime}$ is not necessarily $t-1$. $\Delta_{c,\left(t^{\prime}, t\right)} X_{i s}$ is $\ln A g e_{i c s t}-\ln A g e_{i(c-1) s t^{\prime}}$. As an example, if $i$, born on April 10, 1986, competed at the World Cup competition in Park City, Utah, USA in the 2009/10 season on November 12 and at the World Cup in Lake Placid, NY, USA, which was the next competition that took place on November 20 , then $\Delta_{c,\left(t^{\prime}, t\right)} X_{i s}$ is $\ln (8625)-\ln (8617)$. It is widely known that times may vary slightly by heat because an athlete can become accustomed to the track as the number of heats increases and the quality of the ice can change over the course of the event. In order to control for the potential increase in $\ln y 2_{\text {ihcs }}$ according to the number of heats, we include $\operatorname{Heat} 2_{i h\left(c^{\prime}, c\right) s\left(t^{\prime}, t\right)}$, a dummy variable taking a value 1 if $h=2$.

For $s=$ Olympics/WCHs, the differenced model is

$$
\begin{aligned}
\left(\mathrm{MO}_{2}\right) \Delta_{\left(t^{\prime}, t\right)} \ln y 2_{i h s}= & \beta_{H} \Delta_{\left(t^{\prime}, t\right)} \text { Host }_{i s}+\beta_{1} \Delta_{\left(t^{\prime}, t\right)} \ln y 1_{i h s}+\Delta_{\left(t^{\prime}, t\right)} X_{i s} \beta_{X} \\
& +\beta_{p} \Delta_{\left(t^{\prime}, t\right)} \text { track_possess }_{i s}+\Delta_{\left(t^{\prime}, t\right)} Z_{s} \beta_{Z}+\beta_{o} \Delta_{\left(t^{\prime}, t\right)} \text { Olympics }_{i s} \\
& +\sum_{R=2}^{4} \beta_{R}^{\text {Heat }} \text { Heat } R_{i h s\left(t^{\prime}, t\right)}+\epsilon_{i h s\left(t^{\prime}, t\right)} .
\end{aligned}
$$

There is only one competition in each season so we do not need $\left(c^{\prime}, c\right)$ and can omit $c$ in 
the model. For example, $\Delta_{c,\left(t^{\prime}, t\right)}=\Delta_{\left(t^{\prime}, t\right)}$. Furthermore, because we take data from athletes who participated in two consecutive Olympics/WCHs games, $\left(t^{\prime}, t\right)=(t-1, t)$ regardless

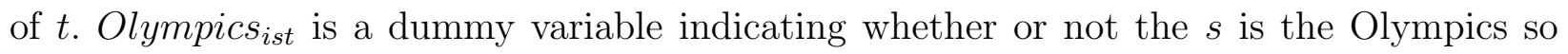
$\Delta_{\left(t^{\prime}, t\right)}$ Olympics $_{i s}=$ Olympics $_{i s t}-$ Olympics $_{i s t^{\prime}}$ is 1 if $i$ competed at the Olympics in season $t$ and at the WCH in season $t^{\prime}=t-1,-1$ if $i$ competed at the WCH in season $t$ and at the Olympics in season $t^{\prime}=t-1$, and 0 if $i$ competed at the $\mathrm{WCH}$ in both seasons. Because Olympics $=1$ every four seasons, Olympics $=$ Season $4+$ Season $8+$ Season 12. Therefore, having Olympics and the season dummies together on the righthand side leads to perfect multicollinearity. We thus omit the season dummies from the model (8). Depending on their performance, athletes can participate in up to four heats in the Olympics and WCH so we included Heat $3_{i h s\left(t^{\prime}, t\right)}$ and Heat $4_{i h s\left(t^{\prime}, t\right)}$, in addition to Heat $2_{i h s\left(t^{\prime}, t\right)}$, where Heat $R_{i h s\left(t^{\prime}, t\right)}$ is 1 if $h=R$ and 0 if $h \neq R$ for $R=2,3,4$.

\subsection{Model for the Crowd Effect}

In this model, the response variable is $\ln y 1$. The model for $\ln y 1$ that we use is

$$
\begin{aligned}
\ln y 1_{\text {ihcst }} & =\beta_{0, h}+\beta_{H} \text { Host }_{i c s t}+X_{\text {icst }} \beta_{X}+\beta_{p} \text { track_possess }_{i c s t} \\
& +Z_{c s t} \beta_{Z}+\sum_{\tau \neq 2} \beta_{\tau}^{\text {season }} \text { Seasont }_{i c t}+\varepsilon_{\text {ihcst }} .
\end{aligned}
$$

$X$ is $\ln$ Age as in Section 4.1. For $Z$, we only use the altitude of the starting point (Altitude) because there is very little difference in the first 50 meters of the available tracks other than their altitudes. Obviously, we do not use $\ln y 1$ on the righthand side. 
The differenced model used to identify the size of the crowd effect is

$$
\begin{aligned}
\left(\mathrm{MD}_{1}\right) \Delta_{c,\left(t^{\prime}, t\right)} \ln y 2_{i h s}= & \beta_{H} \Delta_{c,\left(t^{\prime}, t\right)} \text { Host }_{i s}+\Delta_{c,\left(t^{\prime}, t\right)} X_{i s} \beta_{X} \\
& +\beta_{p} \Delta_{c,\left(t^{\prime}, t\right)} \text { track_possess }_{i s}+\Delta_{c,\left(t^{\prime}, t\right)} Z_{s} \beta_{Z} \\
& +\sum_{\tau \neq 2} \beta_{\tau}^{\text {season }} \Delta_{c,\left(t^{\prime}, t\right)} \text { Season }_{i} \\
& +\beta_{2}^{\text {Heat }} \operatorname{Heat}_{\text {ih }\left(c^{\prime}, c\right) s\left(t^{\prime}, t\right)}+\epsilon_{\text {ih }\left(c^{\prime}, c\right) s\left(t^{\prime}, t\right)}
\end{aligned}
$$

for $s=\mathrm{WC}$, ICC, NAC, and EC and

$$
\begin{aligned}
\left(\mathrm{MO}_{1}\right) \Delta_{t} \ln y 1_{i h s}= & \beta_{H} \Delta_{t} \text { Host }_{i s}+\Delta_{t} X_{i s} \beta_{X} \\
& +\beta_{p} \Delta_{t} \text { track_possess }_{i s}+\Delta_{t} Z_{s} \beta_{Z}+\beta_{o} \Delta_{t} \text { Olympics }_{i s} \\
& +\sum_{R=2}^{4} \beta_{R}^{\text {Heat }} \operatorname{Heat}_{\text {ihs }(t-1, t)}+\epsilon_{i h s(t-1, t)},
\end{aligned}
$$

for $s=$ Olympics/WCH.

\section{Results}

\subsection{Results for the Familiarity Effect}

We first discuss home advantage arising from familiarity with the track. Let us begin with the result for Model $\left(\mathrm{MO}_{2}\right)$ presented in Table 5. The estimates for all but the second heat are statistically significant at a $1 \%$ level.

The coefficient estimate for Host is 0.0045 , so the size of the home advantage from familiarity with the track is approximately $0.45 \%$-points. It means that a home athlete's speed in the sliding stage is $0.45 \%$ faster in a home race than away in every heat 1 Obviously, a $0.45 \%$ increase in speed is approximately a $0.45 \%$ decrease in the sliding stage time in every

\footnotetext{
${ }^{1}$ The size of the overall home advantage is discussed in Section 5.3 .
} 
Table 5: Familiarity effect in the Olympics and WCH $\left(\mathrm{MO}_{2}\right)$

\begin{tabular}{lcc}
\hline & Estimate & Standard Error \\
\hline$\Delta$ Host & $0.0045^{* * *}$ & 0.0017 \\
$\Delta \ln y 1$ & $0.3749^{* * *}$ & 0.0234 \\
$\Delta \ln ($ Age $)$ & $0.2661^{* * *}$ & 0.0270 \\
$\Delta$ Track_possess & $0.0127^{* * *}$ & 0.0022 \\
\hline$\Delta \ln ($ Length $)$ & $0.0542^{* * *}$ & 0.0148 \\
$\Delta \ln ($ Average & $-0.0287^{* * *}$ & 0.0039 \\
gradient) & & \\
$\Delta \ln ($ Vertical drop) & $0.1598^{* * *}$ & 0.0078 \\
$\Delta$ Number of curves & $0.0169^{* * *}$ & 0.0005 \\
$\Delta \ln ($ Altitude) & $-0.0586^{* * *}$ & 0.0016 \\
\hline$\Delta$ Olympics & $0.0549^{* * *}$ & 0.0020 \\
\hline Heat2 & $-0.0014^{*}$ & 0.0008 \\
Heat3 & $-0.0037^{* * *}$ & 0.0010 \\
Heat4 & $-0.0051^{* * *}$ & 0.0012 \\
\hline$N$ & \multicolumn{2}{c}{1515} \\
R-squared & \multicolumn{2}{|}{} \\
\hline
\end{tabular}

Notes. ${ }^{* * *} p<.01,{ }^{* *} p<.05,{ }^{*} p<.10$.

heat, providing that all other factors are controlled for. A $0.45 \%$ decrease in the sliding stage time is not trivial. For example, the average sliding stage times for the silver and bronze medalists in the 2018 Pyeongchang Winter Olympics were 45.8 and 45.6725 seconds. The silver medalist was thus only $0.28 \%$ slower than the bronze medalist.

A $1 \%$ increase in the pushing stage speed results in about a $0.37 \%$ increase in the sliding stage speed, thus confirming that the momentum gathered by the sprint in the starting area is vital to the final performance. $\beta_{o}$ is estimated to be 0.0549 , which means times in the Olympics are $5.49 \%$ faster on average than those in the WCH. We believe that this reflects the increase in motivation due to the prestige and importance of the Olympics. $\beta_{p}$, the coefficient for Track_possess, is estimated to be 0.0127 , indicating that access to training infrastructure benefits athletes in the Olympics and WCH. The coefficient estimate for ln Age is 0.2661 , meaning the older the athlete, the faster they are. 
Table 6: Familiarity effect in the WC, ICC, NAC, and EC $\left(\mathrm{MD}_{2}\right)$

\begin{tabular}{|c|c|c|c|c|c|c|c|c|}
\hline & \multicolumn{2}{|c|}{ WC } & \multicolumn{2}{|c|}{ ICC } & \multicolumn{2}{|c|}{ NAC } & \multicolumn{2}{|c|}{ EC } \\
\hline & Estimate & $\mathrm{SE}$ & Estimate & SE & Estimate & $\mathrm{SE}$ & Estimate & SE \\
\hline$\Delta$ Host & $0.0097^{* * *}$ & 0.0032 & $0.0164^{* * *}$ & 0.0039 & $0.0060^{* * *}$ & 0.0017 & $0.0184^{* * *}$ & 0.0038 \\
\hline$\Delta \ln y 1$ & $0.4263^{* * *}$ & 0.0149 & $0.5458^{* * *}$ & 0.1011 & $0.1948^{* * *}$ & 0.0304 & $0.1548^{* * *}$ & 0.0412 \\
\hline$\Delta \ln ($ Age $)$ & 0.3154 & 0.3447 & -0.5956 & 0.4375 & $-0.3228^{*}$ & 0.1832 & $-0.3614^{*}$ & 0.2137 \\
\hline $\begin{array}{l}\Delta \text { Track }_{-} \\
\text {possess }\end{array}$ & 0.0009 & 0.0035 & $-0.0170^{* * *}$ & 0.0026 & -0.0070 & 0.0046 & 0.0042 & 0.0064 \\
\hline$\Delta \ln ($ Length $)$ & $-0.0332^{* * *}$ & 0.0063 & $-0.2073^{* * *}$ & 0.0590 & 0.0662 & 0.0430 & $-0.1134^{* * *}$ & 0.0238 \\
\hline $\begin{array}{l}\Delta \ln (\text { Average } \\
\text { gradient) }\end{array}$ & $0.0298^{* * *}$ & 0.0061 & $-0.6416^{* * *}$ & 0.0600 & $0.1466^{* * *}$ & 0.0301 & $-0.3490^{* * *}$ & 0.0460 \\
\hline $\begin{array}{l}\Delta \ln (\text { Vertical } \\
\text { drop) }\end{array}$ & $0.0540 * * *$ & 0.0052 & $0.2015^{* * *}$ & 0.0177 & $-0.0995^{* * *}$ & 0.0243 & $-0.0907^{* *}$ & 0.0377 \\
\hline $\begin{array}{l}\Delta \text { Number } \\
\text { of curves }\end{array}$ & $0.0145^{* * *}$ & 0.0003 & $0.0140^{* * *}$ & 0.0017 & \multicolumn{2}{|c|}{$(\text { omitted })^{\mathrm{a}}$} & $0.0147^{* * *}$ & 0.0009 \\
\hline$\Delta \ln ($ Altitude $)$ & $0.0319^{* * *}$ & 0.0017 & -0.0135 & 0.0088 & \multicolumn{2}{|c|}{$(\text { omitted })^{\mathrm{a}}$} & $0.0308^{* * *}$ & 0.0052 \\
\hline$\Delta$ Season1 & -0.0052 & 0.0108 & \multicolumn{2}{|c|}{ (Did not exist) } & $0.0226^{* *}$ & 0.0091 & $-0.0463^{* * *}$ & 0.0100 \\
\hline$\Delta$ Season3 & 0.0001 & 0.0099 & $-0.0321^{* *}$ & 0.0148 & 0.0094 & 0.0059 & $0.0348^{* * *}$ & 0.0092 \\
\hline$\Delta$ Season 4 & -0.0189 & 0.0187 & $-0.0977^{* * *}$ & 0.0295 & $0.0531^{* * *}$ & 0.0110 & $0.1437^{* * *}$ & 0.0180 \\
\hline$\Delta$ Season5 & $0.0737^{* *}$ & 0.0299 & $-0.1237^{* * *}$ & 0.0457 & $0.0655^{* * *}$ & 0.0172 & $0.1651^{* * *}$ & 0.0262 \\
\hline$\Delta$ Season6 & $0.0895^{* *}$ & 0.0393 & $-0.1564^{* *}$ & 0.0625 & $0.0635^{* * *}$ & 0.0235 & $0.1719^{* * *}$ & 0.0354 \\
\hline$\Delta$ Season 7 & $0.0882^{*}$ & 0.0491 & $-0.1728^{* *}$ & 0.0758 & $0.0774^{* * *}$ & 0.0295 & $0.1712^{* * *}$ & 0.0447 \\
\hline$\Delta$ Season8 & $0.1307^{* *}$ & 0.0594 & $-0.2004^{* *}$ & 0.0908 & $0.0894^{* *}$ & 0.0354 & $0.1846^{* * *}$ & 0.0526 \\
\hline$\Delta$ Season9 & $0.2230 * * *$ & 0.0708 & $-0.2793^{* * *}$ & 0.1006 & $0.1032^{* *}$ & 0.0429 & $0.3052^{* * *}$ & 0.0620 \\
\hline$\Delta$ Season 10 & $0.2244^{* * *}$ & 0.0818 & $-0.2435^{* *}$ & 0.1147 & $0.1189^{* *}$ & 0.0475 & $0.3833^{* * *}$ & 0.0701 \\
\hline$\Delta$ Season11 & $0.3214^{* * *}$ & 0.0917 & $-0.2432^{*}$ & 0.1290 & $0.1374^{* * *}$ & 0.0521 & $0.3872^{* * *}$ & 0.0803 \\
\hline$\Delta$ Season12 & $0.2820^{* * *}$ & 0.1002 & -0.2104 & 0.1408 & $0.1509^{* *}$ & 0.0580 & $0.4437 * * *$ & 0.0909 \\
\hline$\Delta$ Season13 & $0.3299 * * *$ & 0.1143 & -0.2361 & 0.1549 & $0.2402^{* * *}$ & 0.0645 & $0.4850^{* * *}$ & 0.1006 \\
\hline Heat2 & $-0.0027^{* * *}$ & 0.0004 & $0.0062^{* * *}$ & 0.0005 & $0.0007^{* *}$ & 0.0003 & -0.0002 & 0.0007 \\
\hline$N$ & \multicolumn{2}{|c|}{7411} & \multicolumn{2}{|c|}{5366} & \multicolumn{2}{|c|}{4319} & \multicolumn{2}{|c|}{6167} \\
\hline R-squared & \multicolumn{2}{|c|}{0.5124} & \multicolumn{2}{|c|}{0.3892} & \multicolumn{2}{|c|}{0.1302} & \multicolumn{2}{|c|}{0.4010} \\
\hline
\end{tabular}

Notes. ${ }^{\text {a }}$ Omitted due to multicollinearity.

${ }^{* * *} p<.01,{ }^{* *} p<.05,{ }^{*} p<.10$.

The results for $\left(\mathrm{MD}_{2}\right)$ for $s=\mathrm{WC}, \mathrm{ICC}, \mathrm{NAC}$, and EC are presented in Table 6. The coefficient estimates for Host are 0.0060-0.0184, which means that the size of the familiarity effect in these series is $0.6-1.84 \%$-points. Compared to the $0.45 \%$-points for the Olympics and $\mathrm{WCH}$, this relatively large home advantage might be due to the relatively large variation in athlete quality. For example, lower-tier athletes who cannot participate in top series lack 
steering skills, so they are more susceptible to changes in track characteristics, and will thus perform much better on a home track that they are familiar with. On the other hand, top-tier athletes in the Olympics and WCH are likely to have already experienced a track in other series and be familiar with it, which means the advantage of familiarity is smaller for home athletes.

The signs of the coefficients for $\ln y 1$ are as expected for all series, although their sizes differ remarkably between series. The coefficients for $\ln$ Age are not as significant as for the Olympics and WCH and, interestingly, their signs are the opposite of what was anticipated for the ICC, NAC, and EC. These results could be explained by the relatively large range of ages among the athletes who compete in the series, in addition to their increased diversity of their experiences, abilities, and possibly the strength of their motivation. This diversity may explain the coefficients for Track_possess as well.

With the exception of the ICC, $\beta_{\tau}^{\text {season }}$ (the coefficient for the season dummies) increases overall which means that the average sliding stage speed increased over the 13 years in the $\mathrm{WC}, \mathrm{NAC}$, and EC series. The $\beta_{13}^{\text {season }}-\beta_{1}^{\text {season }}$ for the WC is estimated to be 0.3351 , which means the average sliding stage speed in the WC increased by about $2.58 \%$-points every year. Similar calculations reveal a 1.67\%-point increase for the NAC and a 4.09\%-point increase for the EC every year. However, the average sliding stage speed in the ICC decreased about $1.97 \%$-points every year over the 12 year period. Though the ICC exception is interesting, we do not attempt to explain the reasons for it in this paper and instead focus on the home advantage effect.

\subsection{Results for the Crowd Effect}

The estimation results for model $\mathrm{MO}_{1}$ are presented in Table 7. The crowd effect in relation to the home advantage for $s=$ Olympics/WCH is estimated to be $1.03 \%$-points. The estimate of $\beta_{o}$ is positive and significant, which suggests that the Olympics leads to faster sprints than the WCH. The effect of an athlete's nation having a track on $y 1$ is small and insignificant. 
In a sense, this is as expected because practicing for the sprint can be done without a track. The coefficient for ln Age is positive, which again means that the older athletes were faster.

Table 7: Crowd effect in the Olympics and WCH $\left(\mathrm{MO}_{1}\right)$

\begin{tabular}{lcc}
\hline & Estimate & Standard Error \\
\hline$\Delta$ Host & $0.0103^{* *}$ & 0.0043 \\
$\Delta \ln ($ Age $)$ & $0.3132^{* * *}$ & 0.0403 \\
$\Delta$ Track_possess & 0.0026 & 0.0233 \\
\hline$\Delta \ln ($ Altitude $)$ & $0.0402^{* * *}$ & 0.0022 \\
\hline$\Delta$ Olympics & $0.0449^{* * *}$ & 0.0038 \\
\hline Heat2 & $-0.0033^{* * *}$ & 0.0010 \\
Heat3 & -0.0010 & 0.0010 \\
Heat4 & -0.0021 & 0.0016 \\
\hline$N$ & & 1515 \\
R-squared & \multicolumn{3}{c}{0.3883} \\
\hline
\end{tabular}

Notes. ${ }^{* * *} p<.01,{ }^{* *} p<.05,{ }^{*} p<.10$.

Table 8 presents the results for the estimation of $\mathrm{MD}_{1}$ for $s=\mathrm{WC}, \mathrm{ICC}, \mathrm{NAC}$, and EC. The estimate of $\beta_{H}$ for the $\mathrm{WC}$ is 0.0104 and significant, meaning that the crowd effect for the WC is $1.04 \%$-points and statistically significant. The size of the crowd effect for the $\mathrm{WC}$ is almost the same as that for the Olympics/WCH. However, the estimates of $\beta_{H}$ for the development circuits are smaller in size and insignificant. Compared to the Olympics, $\mathrm{WCH}$, and $\mathrm{WC}$, the crowd size in these series may not be large enough for crowd support to generate a noticeable difference in performance due to the lack of importance and attention, although the exact numbers of spectators in these competitions are not available.

The coefficient estimates for the other control variables are difficult to explain. For example, the coefficient for $\ln$ Age for the EC is negative and significant, the coefficient for Track_possess for the WC is significantly negative, and the season dummies for the WC and ICC are generally negative and significant. One possibility is that there are more young and less experienced athletes competing in the WC and ICC as the seasons pass, but we do not attempt to explain these results in this paper. 
Table 8: Crowd effect in the WC, ICC, NAC, and EC $\left(\mathrm{MD}_{1}\right)$

\begin{tabular}{|c|c|c|c|c|c|c|c|c|}
\hline & \multicolumn{2}{|c|}{ WC } & \multicolumn{2}{|c|}{ ICC } & \multicolumn{2}{|c|}{$\mathrm{NAC}$} & \multicolumn{2}{|c|}{$\mathrm{EC}$} \\
\hline & Estimate & $\mathrm{SE}$ & Estimate & $\mathrm{SE}$ & Estimate & $\mathrm{SE}$ & Estimate & $\mathrm{SE}$ \\
\hline$\Delta$ Host & $0.0104^{* * *}$ & 0.0035 & 0.0069 & 0.0043 & 0.0020 & 0.0038 & 0.0045 & 0.0035 \\
\hline$\Delta \ln ($ Age $)$ & $3.2607^{* * *}$ & 0.3876 & $2.0206^{* * *}$ & 0.6390 & 0.3206 & 0.3534 & $-2.3002^{* * *}$ & 0.3052 \\
\hline $\begin{array}{l}\Delta \text { Track }_{-} \\
\text {possess }\end{array}$ & $-0.0167^{* *}$ & 0.0064 & -0.0069 & 0.0061 & 0.0121 & 0.0077 & -0.0092 & 0.0088 \\
\hline$\Delta \ln ($ Altitude $)$ & $0.0288^{* * *}$ & 0.0019 & $0.0536^{* * *}$ & 0.0030 & $0.0413^{* * *}$ & 0.0021 & $0.0138^{* * *}$ & 0.0030 \\
\hline$\Delta$ Season1 & $0.1657^{* * *}$ & 0.0125 & \multicolumn{2}{|c|}{ (Did not exist) } & $0.0855^{* * *}$ & 0.0179 & $-0.1090^{* * *}$ & 0.0131 \\
\hline$\Delta$ Season3 & $-0.0937^{* * *}$ & 0.0119 & $-0.1009^{* * *}$ & 0.0235 & $0.0187^{*}$ & 0.0108 & $0.1066^{* * *}$ & 0.0136 \\
\hline$\Delta$ Season4 & $-0.1722^{* * *}$ & 0.0230 & $-0.1832^{* * *}$ & 0.0441 & 0.0321 & 0.0229 & $0.2047^{* * *}$ & 0.0254 \\
\hline$\Delta$ Season 5 & $-0.1830^{* * *}$ & 0.0355 & $-0.2525^{* * *}$ & 0.0657 & 0.0529 & 0.0324 & $0.3463^{* * *}$ & 0.0376 \\
\hline$\Delta$ Season6 & $-0.3428^{* * *}$ & 0.0474 & $-0.3661^{* * *}$ & 0.0908 & $0.0736^{*}$ & 0.0437 & $0.5289^{* * *}$ & 0.0491 \\
\hline$\Delta$ Season7 & $-0.4108^{* * *}$ & 0.0576 & $-0.3597 * * *$ & 0.1112 & $0.1136^{* *}$ & 0.0544 & $0.6989^{* * *}$ & 0.0628 \\
\hline$\Delta$ Season8 & $-0.5751^{* * *}$ & 0.0684 & $-0.4372^{* * *}$ & 0.1325 & 0.0847 & 0.0649 & $0.8205^{* * *}$ & 0.0744 \\
\hline$\Delta$ Season9 & $-0.7069^{* * *}$ & 0.0797 & $-0.3792^{* *}$ & 0.1558 & 0.0965 & 0.0772 & $0.9869^{* * *}$ & 0.0864 \\
\hline$\Delta$ Season10 & $-0.9004^{* * *}$ & 0.0904 & $-0.4013^{* *}$ & 0.1757 & 0.0888 & 0.0873 & $1.0660^{* * *}$ & 0.0988 \\
\hline$\Delta$ Season11 & $-0.9596^{* * *}$ & 0.1003 & $-0.4853^{* *}$ & 0.1951 & 0.0532 & 0.0965 & $1.2442^{* * *}$ & 0.1113 \\
\hline$\Delta$ Season12 & $-1.0618^{* * *}$ & 0.1094 & $-0.4746^{* *}$ & 0.2131 & 0.1259 & 0.1048 & $1.4426^{* * *}$ & 0.1247 \\
\hline$\Delta$ Season13 & $-1.1126^{* * *}$ & 0.1207 & $-0.4967^{* *}$ & 0.2329 & 0.1704 & 0.1145 & $1.5864^{* * *}$ & 0.1368 \\
\hline Heat 2 & $-0.0031^{* * *}$ & 0.0007 & $-0.0036^{* * *}$ & 0.0006 & -0.0007 & 0.0007 & $-0.0030^{* * *}$ & 0.0008 \\
\hline$N$ & \multicolumn{2}{|c|}{7411} & \multicolumn{2}{|c|}{5366} & \multicolumn{2}{|c|}{4319} & \multicolumn{2}{|c|}{6167} \\
\hline R-squared & \multicolumn{2}{|c|}{0.1218} & \multicolumn{2}{|c|}{0.2105} & \multicolumn{2}{|c|}{0.2754} & \multicolumn{2}{|c|}{0.0778} \\
\hline
\end{tabular}

Notes. ${ }^{* * *} p<.01,{ }^{* *} p<.05,{ }^{*} p<.10$.

\subsection{Overall home advantage}

We can combine the familiarity and crowd effects to compute the size of the overall home advantage. Let $T$ be the final time and $T_{1}$ be the start time and define $T_{2}:=T-T_{1}$, $S_{1}:=y_{1} T_{1}$, and $S_{2}:=y_{2} T_{2}$. Then, assuming $S_{1}$ and $S_{2}$ are fixed,

$$
\begin{aligned}
-d \ln T & =-d \ln \left(T_{1}+T_{2}\right)=-\frac{1}{T}\left(d T_{1}+d T_{2}\right)=-\frac{1}{T}\left(d\left(\frac{S_{1}}{y_{1}}\right)+d\left(\frac{S_{2}}{y_{2}}\right)\right) \\
& =-\frac{1}{T}\left(\frac{S_{1}}{y_{1}} d \ln \left(\frac{1}{y_{1}}\right)+\frac{S_{2}}{y_{2}} d \ln \left(\frac{1}{y_{2}}\right)\right)=\frac{T_{1}}{T} d \ln y_{1}+\frac{T-T_{1}}{T} d \ln y_{2},
\end{aligned}
$$

where $-d \ln T$ may read $-\frac{\text { final time with home advantage-final time without home advantage }}{\text { final time without home advantage }}$ approximately, which is the overall home advantage in terms of time. Considering the fact that the speed 
increases in the sliding stage due to the familiarity effect and the faster speed at the pushing stage due to the crowd effect, we can interpret (12) as

$$
\begin{aligned}
& \text { total home advantage }(\% \text {-point })=\frac{\text { start time }}{\text { final time }} \times \text { crowd factor }(\% \text {-point }) \\
& +\frac{\text { final time }- \text { start time }}{\text { final time }} \times\left(\text { familiarity factor }(\% \text {-point })+\beta_{1} \times \text { crowd factor }(\% \text {-point })\right) \\
& =\left(\beta_{1}+\left(1-\beta_{1}\right) \frac{\text { start time }}{\text { final time }}\right) \times \text { crowd factor }(\% \text {-point }) \\
& +\left(1-\frac{\text { start time }}{\text { final time }}\right) \times \text { familiarity factor }(\% \text {-point })
\end{aligned}
$$

The relative importance of the crowd and familiarity effects for overall home advantage may

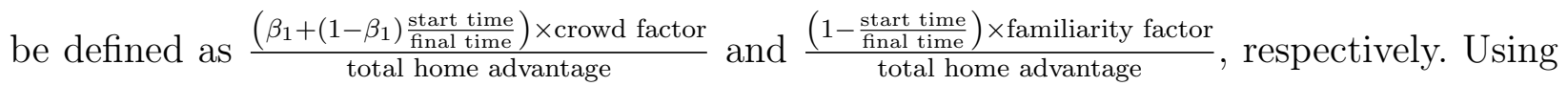
the average times of $T_{1} / T$, we can calculate the overall home advantage for each series (see Table 9).

Table 9: Overall home advantage (\%-point)

\begin{tabular}{c|c|c|c|c|c}
\hline Series & $\operatorname{Avg} \frac{T_{1}}{T}$ & $\hat{\beta}_{1}$ & Crowd f. & Familiarity f. & Total HA \\
\hline Olympics/WCH & 0.0896 & 0.3749 & $1.03(0.520)$ & $0.45(0.480)$ & 0.8535 \\
WC & 0.0914 & 0.4263 & $1.04(0.361)$ & $0.97(0.639)$ & 1.3792 \\
ICC & 0.0935 & 0.5458 & $0.69(0.214)$ & $1.64(0.786)$ & 1.8926 \\
NAC & 0.0939 & 0.1948 & $0.20(0.090)$ & $0.60(0.910)$ & 0.5977 \\
EC & 0.0927 & 0.1548 & $0.45(0.059)$ & $1.84(0.941)$ & 1.7743 \\
\hline
\end{tabular}

Notes. Figures in ( ) are the relative importance.

In the Olympics and $\mathrm{WCH}$, athletes seem to benefit by about $0.854 \%$-points on average from home advantage, of which $0.444 \%$-points are due to the crowd effect and $0.410 \%$-points are due to the familiarity effect. Thus, unlike other series, the relative importance of the crowd support is greater than the familiarity with the track for average athletes in the Olympics and WCH. In the other series, the relative importance of familiarity with the track is greater. The size of the overall home advantage is the lowest in the NAC. The relative importance of the crowd support is in the order of Olympics/WCH $>\mathrm{WC}>\mathrm{ICC}>\mathrm{NAC}$ 
$>$ EC, with the Olympics/WCH standing out from the others in this respect.

\section{Conclusion}

Of the four known factors that affect home advantage, we selected the two that are most influential in skeleton and estimated the size of their effect: crowd support and familiarity with the track. Due to the limited crowd capacity at sledding tracks and the fast speed of a sled, crowd support affects an athlete's performance only in the first 50 meters where the athlete sprints to gather speed. The familiarity effect, on the other hand, is the main driver of home advantage for the rest of the track because steering skill determines performance after the sprint. The other two factors, travel and home-ground rules, are not likely to occur in skeleton.

In order to separate out the two factors, we used IBSF times for the first 50 meters and the entire race from athletes who competed in two consecutive competitions in a given series so that, by employing differenced econometric models, we were able to eliminate individual and series-specific heterogeneities that may obscure the effects of home advantage. The size of home advantage differed by series. Athletes in the Olympics and World Championships benefit from about a $0.854 \%$ reduction in their final time on average thanks to home advantage, of which $0.444 \%$-points are due to the crowd effect and the remaining $0.410 \%$-points are due to the familiarity effect. Athletes in the World Cup have about a 1.379\% reduction in their final time on average, of which $0.498 \%$-points are due to the crowd effect and $0.881 \%$ points are due to the familiarity effect. The Intercontinental Cup, North American Cup, and European Cup differed in the extent of home advantage. In the Olympics and World Championships, the crowd support out-contributes track familiarity for average athletes. In the other series, however, familiarity is much more influential. We also found that athletes are faster on average in the Olympics than in the World Championships, which represents the motivational effect of the Olympics. 


\section{References}

Balmer, N. J., Nevill, A. M., \& Lane, A. M. (2005). Do judges enhance home advantage in european championship boxing? Journal of Sports Sciences, 23(4), 409-416.

Balmer, N. J., Nevill, A. M., \& Williams, A. M. (2001). Home advantage in the winter olympics (1908-1998). Journal of Sports Sciences, 19(2), 129-139.

Balmer, N. J., Nevill, A. M., \& Williams, A. M. (2003). Modelling home advantage in the summer olympic games. Journal of sports sciences, 21 (6), 469-478.

Boudreaux, C. J., Sanders, S. D., \& Walia, B. (2017). A natural experiment to determine the crowd effect upon home court advantage. Journal of Sports Economics, 18(7), $737-749$.

Boyko, R. H., Boyko, A. R., \& Boyko, M. G. (2007). Referee bias contributes to home advantage in english premiership football. Journal of sports sciences, 25(11), 11851194.

Bray, S., \& Carron, A. (1993). The home advantage in alpine skiing. Australian Journal of Science and Medicine in Sport, 25, 76-76.

Bullock, N., Hopkins, W. G., Martin, D. T., \& Marino, F. E. (2009). Characteristics of performance in skeleton world cup races. Journal of Sports Sciences, 27(4), 367-372.

Clarke, S. R. (2005). Home advantage in the australian football league. Journal of Sports Sciences, 23(4), 375-385.

Clarke, S. R., \& Norman, J. M. (1995). Home ground advantage of individual clubs in english soccer. Journal of the Royal Statistical Society: Series D (The Statistician), $44(4), 509-521$.

Courneya, K. S., \& Carron, A. V. (1990). Batting first versus last: Implications for the home advantage. Journal of Sport and Exercise Psychology, 12(3), 312-316.

Courneya, K. S., \& Carron, A. V. (1992). The home advantage in sport competitions: A literature review. Journal of Sport and Exercise Psychology, 14(1), 13-27.

Dawson, P., \& Dobson, S. (2010). The influence of social pressure and nationality on 
individual decisions: Evidence from the behaviour of referees. Journal of Economic Psychology, 31(2), 181-191.

Dawson, P., Dobson, S., Goddard, J., \& Wilson, J. (2007). Are football referees really biased and inconsistent?: evidence on the incidence of disciplinary sanction in the english premier league. Journal of the Royal Statistical Society: Series A (Statistics in Society), 170(1), 231-250.

Dohmen, T. J. (2008). The influence of social forces: Evidence from the behavior of football referees. Economic inquiry, 46(3), 411-424.

Dowie, J. (1982). Why spain should win the world cup. New Scientist, 94(1309), 693-695.

Ferreira Julio, U., Panissa, V. L. G., Miarka, B., Takito, M. Y., \& Franchini, E. (2013). Home advantage in judo: A study of the world ranking list. Journal of Sports Sciences, 31(2), 212-218.

Goumas, C. (2014). Home advantage in australian soccer. Journal of Science and Medicine in Sport, 17(1), 119-123.

IBSF. (2019a). The international bobsleigh $\mathcal{E}$ skeleton federation athletes. Retrieved March 18, 2019, from http://www.ibsf.org/

IBSF. (2019b). The international bobsleigh \& skeleton federation results. Retrieved March 18, 2019, from http://www.ibsf.org/

IBSF. (2019c). The international bobsleigh \& skeleton federation tracks. Retrieved April 1, 2019, from http://www.ibsf.org/

Koning, R. H. (2005). Home advantage in speed skating: Evidence from individual data. Journal of Sports Sciences, 23(4), 417-427.

Koning, R. H. (2011). Home advantage in professional tennis. Journal of Sports Sciences, 29(1), 19-27.

Krumer, A. (2017). On winning probabilities, weight categories, and home advantage in professional judo. Journal of sports economics, 18(1), 77-96.

LA84-Foundation-Digital-Library. (2019). Official report of the xx olympic winter games - 
results. Retrieved April 1, 2019, from http://digital.la84.org/

Leard, B., \& Doyle, J. M. (2011). The effect of home advantage, momentum, and fighting on winning in the national hockey league. Journal of Sports Economics, 12(5), 538-560.

Loughead, T. M., Carron, A. V., Bray, S. R., \& Kim, A. J. (2003). Facility familiarity and the home advantage in professional sports. International Journal of Sport and Exercise Psychology, 1(3), 264-274.

McCutcheon, L. E. (1984). The home advantage in high school athletics. Journal of Sport Behavior, 7(4), 135.

Moore, J. C., \& Brylinsky, J. (1995). Facility familiarity and the home advantage. Journal of Sport Behavior, 18(4), 302.

Morton R, H. (2006). Home advantage in southern hemisphere rugby union: Nationaland international. Journal of Sports Sciences, 24(05), 495-499.

Nichols, M. W. (2014). The impact of visiting team travel on game outcome and biases in nfl betting markets. Journal of Sports Economics, 15(1), 78-96.

Nutting, A. W. (2010). Travel costs in the nba production function. Journal of Sports Economics, 11(5), 533-548.

Oberhofer, H., Philippovich, T., \& Winner, H. (2010). Distance matters in away games: Evidence from the german football league. Journal of Economic Psychology, 31(2), 200-211.

Picazo-Tadeo, A. J., González-Gómez, F., \& Guardiola, J. (2017). Does the crowd matter in refereeing decisions? evidence from spanish soccer. International Journal of Sport and Exercise Psychology, 15(5), 447-459.

Pollard, R. (1986). Home advantage in soccer: A retrospective analysis. Journal of sports sciences, 4(3), 237-248.

Pollard, R. (2002). Evidence of a reduced home advantage when a team moves to a new stadium. Journal of Sports Sciences, 20(12), 969-973.

Pollard, R., \& Gómez, M. A. (2014). Components of home advantage in 157 national soccer 
leagues worldwide. International Journal of Sport and Exercise Psychology, 12(3), $218-233$.

Pollard, R., \& Pollard, G. (2005). Long-term trends in home advantage in professional team sports in north america and england (1876-2003). Journal of sports sciences, 23(4), $337-350$.

Ponzo, M., \& Scoppa, V. (2018). Does the home advantage depend on crowd support? evidence from same-stadium derbies. Journal of Sports Economics, 19(4), 562-582.

Rooney, L., \& Kennedy, R. (2018). Home advantage in gaelic football: the effect of divisional status, season and team ability. International Journal of Performance Analysis in Sport, 18(6), 917-925.

Schwartz, B., \& Barsky, S. F. (1977). The home advantage. Social forces, 55(3), 641-661.

Scoppa, V. (2015). Fatigue and team performance in soccer: Evidence from the fifa world cup and the uefa european championship. Journal of Sports Economics, 16(5), 482-507.

Sutter, M., \& Kocher, M. G. (2004). Favoritism of agents-the case of referees' home bias. Journal of Economic Psychology, 25(4), 461-469.

Zanoletti, C., La Torre, A., Merati, G., Rampinini, E., \& Impellizzeri, F. M. (2006). Relationship between push phase and final race time in skeleton performance. Journal of Strength and Conditioning Research, 20(3), 579. 